\title{
Leishmaniasis Beyond East Africa
}

\author{
Caitlin M. Jones ${ }^{1,2}$ and Susan C. Welburn ${ }^{1,2 *}$ \\ ' Zhejiang University-University of Edinburgh Institute, Zhejiang University School of Medicine, International Campus, Zhejiang \\ University, Haining, China, ${ }^{2}$ Infection Medicine, Deanery of Biomedical Sciences, Edinburgh Medical School, College of \\ Medicine and Veterinary Medicine, The University of Edinburgh, Edinburgh, United Kingdom
}

\section{OPEN ACCESS}

Edited by:

Alessia Libera Gazzonis,

University of Milan, Italy

Reviewed by:

Amir Ahmad Akhavan,

Tehran University of Medical

Sciences, Iran

Roberta latta,

University of Bari Aldo Moro, Italy

*Correspondence:

Susan C. Welburn

sue.welburn@ed.ac.uk

Specialty section:

This article was submitted to Parasitology,

a section of the journal

Frontiers in Veterinary Science

Received: 18 October 2020

Accepted: 15 January 2021

Published: 26 February 2021

Citation:

Jones CM and Welburn SC (2021) Leishmaniasis Beyond East Africa.

Front. Vet. Sci. 8:618766

doi: 10.3389/fvets.2021.618766
Climate change is having a substantial impact on our environment and ecosystems and has altered the way humans live, access, and utilize resources with increased risk of zoonotic infectious disease encounters. As global temperatures continue to increase, they impact on public health, migration, food security and land conflict, and as new environments become favorable, exposure to disease carrying vectors. Increased forests or natural habitat clearance for land repurposing, urbanization, road building, and water management are related to an increase in emerging vector borne parasitic diseases. The East African region remains one of the most impacted regions globally for leishmaniasis, a vector borne disease that impacts significantly on the health, wellbeing and livelihoods of affected communities and for which a lack of reporting and control interventions hinder progress toward elimination of this neglected tropical disease. As our world continues to transform, both politically and climatically, it is essential that measures are put in place to improve surveillance and disease management with implementation of control measures, including vector control, especially in low- and middle-income countries that are expected to be most impacted by changes in climate. Only through effective management, now, can we be sufficiently resilient to preventing the inevitable spread of vectors into suitable habitat and expansion of the geographical range of leishmaniasis. This review offers a current perspective on Leishmaniasis as an endemic disease in East Africa and examines the potential of the recent emergence of Leishmania infection in hitherto unaffected regions to become a public health concern if no disease management is achieved.

Keywords: leishmaniasis, climate, epidemiology, Africa, visceral, cutaneous, vector

\section{BACKGROUND}

Each year, neglected tropical diseases have a substantial impact on upwards of 1 billion people globally, contributing to the damage of economies and impairment of particularly vulnerable communities including those living in extreme poverty (1). The leishmaniases are estimated to affect $0.7-1$ million people, with 350 million people at risk, globally $(2,3)$. Currently, 98 countries are endemic for leishmaniasis (2). Leishmaniasis occurs after the infection of a mammalian host with the obligate, intracellular parasite Leishmania (4). Leishmania species are categorized into either Old World or New World species, corresponding to the different geographical regions in which they are found (5). Old World (OW) species can be found in Asia, the Middle East, the Mediterranean basin and Africa, whereas New World (NW) species are found in the Americas (5). At least 20 Leishmania species are known to cause human disease, of the Leishmania genus and 
Leishmania or Viannia subgenera $(6,7)$. The subgenera were distinguished in the 1980's based on parasite location and site of attachment within the sand-fly gut (7).

Leishmania parasites can infect over 90 sandfly species; the Phlebotomus and Lutzomyia species being most implicated in human leishmaniasis transmission (8). The manifestation of leishmanial disease can occur when parasites are transmitted to the mammalian host upon the infected female sandfly taking a blood meal, which provides the protein required for egg development (9). The dimorphic parasites are transmitted to the human host in their motile, metacyclic promastigote form, invade phagocytic cells-predominantly macrophagesand transform into their non-motile amastigote form (4). Within the cell the amastigotes replicate by binary fission until cell rupture and proceed to further invade healthy neighboring phagocytes (4).

Disease outcome is dependent on a number factors, including parasite species, host genetics and the host immune responses (10). Disease severity can range from cases being serologically positive yet asymptomatic, to cases of disfiguring and fatal infection (11). The three disease forms are characterized as cutaneous, mucocutaneous and visceral leishmaniasis (2). Several complications are also associated, such as postkala-azar dermal leishmaniasis (PKDL), diffuse leishmaniasis, disseminated leishmaniasis and leishmaniasis recidivans (12). Cutaneous leishmaniasis (CL) is considered the mildest and most common form of the disease, and can present as painless nodules, macules, papules or ulcerative lesions on exposed areas of the body $(13,14)$.

There are more than 20 species that cause cutaneous leishmaniasis, most notably the OW species: L. major, L. tropica, L. aethiopica, and the NW species: L. amazonesis, L. braziliensis, L. mexicana, L. panamensis, and L. guyanensis (2, 15). Lesions are local to the site of the sandfly bite and can be self-healing, however the appearance and healing time varies between species (16). While cutaneous lesions due to L. tropica or L. major are likely to self-heal after 12 months, leaving significant scarring, L. aethopica lesions have been shown to become plaque-like and hyperkeratotic, taking many years to heal completely (17, 18). Although not fatal, cutaneous leishmaniasis can lead to serious scarring or disfigurement, which can result in significant psychological stress, including depression and anxiety and social stigmatization leading to a poor quality of life (19-21). Presently, there are 59 countries where the cutaneous form is endemic, 10 of which (Afghanistan, Algeria, Bolivia, Brazil, Colombia, Iran, Iraq, Pakistan, the Syrian Arab Republic and Tunisia) are responsible for $85 \%$ of all recorded cases (22).

Mucocutaneous leishmaniasis (MCL) involves the destruction of mucus membranes and cartilage in the nose, mouth, upper respiratory tract and pharynx, often beginning at the lips and nostrils (23). Although the pathology of MCL is poorly understood, it is thought to be, in part, due to a strong host immunological response $(23,24)$. It has been suggested that parasites may reach mucosa either by haematic or lymphatic spread or are directly injected into the area by the sandfly (23). Symptoms of MCL can arise years after an initial cutaneous lesion has healed, include discharge, congestion, and acute hemorrhage of the nose $(25,26)$. This can be extremely disfiguring as well as life-threatening, potentially leading to complications such as aspiration pneumonia, starvation, sepsis due to secondary infection, and airway obstruction thereby resulting in asphyxia (27). Of all mucocutaneous cases, $90 \%$ are found in Bolivia caused by NW species, however L. aethiopica has also demonstrated the ability to cause MCL in Ethiopia, a country in the OW Region $(2,27)$.

Visceral leishmaniasis (VL) occurs after the systemic spread of Leishmania parasites and can be life-threatening $(28,29)$. VL is characterized by presence of an enlarged liver and spleen, anemia, weight loss, and irregular fevers (2). Patients with VL often die within 2 years of contracting the disease if left untreated, commonly from subsequent infections or severe anemia (30, 31). Although not seen in all VL species it is expected that darkening of the skin, particularly in India, is caused by the cytokine-induced production of adrenocorticotrophic hormone (32). Thus, VL was given the Hindu name kala-azar, meaning "black fever" (33). Two species are known to cause human $\mathrm{VL}$, where $L$. donovani predominantly affects the $\mathrm{OW}$ and $L$. infantum (synonym L. chagasi) the NW regions (34).

There are 59 countries endemic for VL, although cases fall disproportionately on seven of these, with $90 \%$ of all cases found in Brazil, Ethiopia, India, Kenya, Somalia, South Sudan and Sudan (22). There are an estimated 20,000-40,000 deaths annually due to $\mathrm{VL}$, however this figure is likely to be higher as it is likely that the vast majority of VL deaths are not recognized as being caused by leishmaniasis or are not reported (35). Leishmaniasis is well-documented in several countries, including India, which carries one of the highest burdens of leishmaniasis globally, followed by Sudan (36). In other areas of the world, the epidemiology of this disease remains poorly understood.

\section{LEISHMANIASIS, AN ENDEMIC PUBLIC HEALTH PROBLEM IN EAST AFRICA}

In the East African region, cutaneous and visceral leishmaniasis have numerous strongholds across Ethiopia, Sudan, Uganda and Kenya, Somalia, and Eritrea (37).

\section{ETHIOPIA}

Ethiopia is a landlocked country found in the Horn of Africa peninsula (38), endemic for both CL and VL (39). Leishmaniasis has been long established in Ethiopia, with the first scientific reports of CL dating back to 1913 and VL in 1942 (40, 41). It is estimated that Ethiopia accounts for surplus of 30,000-50,000 cases of CL and 3,700-7,400 cases of VL annually $(21,42)$. In the East African region, Ethiopia has the second largest number of VL cases a year, behind Sudan (43). The incidence rate per 10,000 people in endemic areas is 6.28 for VL and 1.05 for CL (44). Nationally, over 28-30 million people are considered to live in areas that put them at risk of contracting leishmaniasis $(45,46)$. The major causative species in this region are L. donovani for VL (though L. infantum has been recorded) and L. aethiopica for CL 
(L. major and L. tropica have also less frequently been reported) $(35,47,48)$. An official country-wide or state level prevalence for either form is not reported, however a recent systematic review reported a national pooled prevalence of $19 \%$ (95\% CI = 14-25\%) (49).

Currently, there is no active case screening for leishmaniasis, only tracking of active cases, and so the basal pool of cases may be much greater than expected $(38,44)$. VL has been identified in eight states: the northern states of Tigray, Amhara, Afar, Benshangul-Gumuz and the southern states of Oromia, Gambella, Somali, and the Southern Nations and Nationalities People's Regional State (SNNPR) (49). There are several wellestablished endemic VL foci, including the Metema and Humera plains in the NW of the country which accounts for around $60 \%$ of cases, as well as the Omo plains and the Weyto Valley in the south (50-52). Approximately $20 \%$ of VL cases occur in the south western savannah and semi-arid lowlands in the SE (53). VL cases have also been recorded in the surrounding areas of Moyale and the Genale river basins in the south of Oromia, in the Afder and Liben zones in the south eastern Somali state and the Awash Valley in the northern state of Afar (43, 49, 54). Despite VL being predominantly found in the lowlands, there have been outbreaks recorded in the previous unaffected highland area of Libo Kemkem (altitude above 2,000 m) in 2005 and Belessa in 1970, both in Amhara $(54,55)$. In contrast to $\mathrm{VL}$, the cutaneous form of disease is strongly associated with the highland regions of Ethiopia where altitudes are above $1,400 \mathrm{~m}$ $(21,51)$. It is expected that CL is present nationally, however well-recognized foci include Ochollo of the Rift Valley, Kutaber district in Amhara, Aleku, Sebeta, the Bale and Sidamo highlands of Oromia, and the Adi-grat and Saesie Tsaedaemba districts of Tigray $(39,56-59)$.

Transmission of Leishmania species that have the potential to cause VL or CL can be zoonotic or anthroponotic [49]. Transmission is not fully understood in Ethiopia, although $L$. aethiopica, which can cause $\mathrm{CL}$, is thought to primarily be zoonotic $[49,56]$. A reservoir for the CL causative agent $L$. aethiopica has been identified as the rock hyrax, with two species primarily involved: Heterohyrax brucei and Procavia capensis $(60,61)$. Transmission of VL caused by L. donovani is generally considered to be anthroponotic in the East African region, however, in Ethiopia it is thought to be partially zoonotic and partially anthroponotic, the nature of which varies with geographical areas (62). Animal reservoirs of Leishmania species causing VL have not been definitively identified, although dogs are likely candidates, as is the case in the neighboring country of Sudan $(54,63)$. Other potential reservoirs are squirrels, wild canids, rodents, reptiles and bats $(39,53,64-66)$.

\section{SUDAN}

To the west of Ethiopia, Sudan is highly endemic for both CL and VL. Although initial reports of VL date back to 1904, it is thought that the Leishmania parasite has been present in Sudan for over 4,000 years, with parasite DNA having been detected in the bone marrow of mummies from this time $(67,68)$. Annually, Sudan accounts for roughly two thirds of all reported VL cases in East Africa (65). Since 2015, around 93\% of the population of Sudan is considered at risk of CL and 25\% at risk of VL (69), despite having incidence rates that are lower than that for Ethiopia in 2015 (3.25 per 10,000 for VL and 0.94 per 10,000 for CL) likely due to significant underreporting at all levels as a function of poor infrastructure (38) and the lack of ability to diagnose cases locally $(38,65,69,70)$. Additionally, this is mirrored in the number of new cases reported in 2015, with only 2,829 cases of VL and 3,503 of CL having been reported by the WHO (69). There is currently no active screening for the control of leishmaniasis in Sudan, but passive case detection and subsequent treatment (71).

The parasite species responsible for VL in Sudan is predominantly $L$. donovani, however, sporadic detection of $L$. archibaldi and L. infantum has occurred in humans and dogs in the State of Gedaref (72). In Sudan, L. donovani is transmitted to the human by the sandfly species $P$. orientalis, though the presence of $P$. martini has also been reported (72). Regions endemic for VL are found in the north and east of Sudan, particularly along the border with northern Ethiopia, including the Sudanese states of Gedaref, Senna, Al Qadarif, and Blue Nile (73). Villages close to the Ethiopian border, concentrated along the Atbarah and Rahad rivers are particularly affected by VL (73). In contrast, CL which is caused by L. major in this region, can be found in the central and western states of Sudan, including Northern and Southern Dafur, Northern and Southern Kordofan, Khartoum, and El Gezira (74). In Sudan, L. major is transmitted by the sandfly species $P$. papatasi $(75,76)$. A recent study utilizing surveillance data reported that the number of CL cases reported from these states in 2014-2017 increased annually, greatly exceeding the estimates reported by the WHO in 2014 (74). Whilst the aforementioned species causing visceral and cutaneous leishmaniasis in Sudan are considered anthroponotic, mammals including the Egyptian mongoose and dogs have also been investigated as parasite reservoir hosts $(63,77,78)$.

\section{KENYA}

$\mathrm{VL}$ is endemic in the arid and semi-arid regions of Kenya including the Rift Valley and provinces in the east and north east of Kenya caused by L. donovani $(79,80)$. Confirmed VL endemic regions are focussed in the arid lowlands, and include Baringo, Turkana, Marakwet, Smaburu, Pokot, Laikipia and Kajiado, Machakos, Mwingi, Meru, Wajir, and Keiyo (79-81). Baringo County is a well-established focus for both CL and VL (82). The West Pokot focus stretches across the border into the Nakapiripirit district of Karamoja region, Uganda, where the most Ugandan cases are concentrated (83). Since its first report in 1935, there have been several epidemics of VL in Kenya, including in the previously unaffected areas of Wajir and Mandera during 2000-2001 (80). It is expected that there are around 4,000 cases of VL annually (84). Over 5 million people in Kenya are considered at risk of exposure to leishmaniasis, with an incidence rate of 2.96 per 10,000 people for VL, however, incidence rate for CL is not reported $(84,85)$. 
In Kenya, the cutaneous form of the disease is deemed endemic by the WHO, however there are a lack of accurate data describing the true extent of disease or case numbers $(85,86)$. CL was first documented in 1969 and is caused by: L. tropica, predominantly found centrally and in the Rift Valley; L. major, reported in the lowlands of Kitui and Baringo (38, 82, 87); and L. aethiopica, detected in areas of high altitudes such as Mount Elgon (88). The vectors responsible for transmission in these regions are Phlebotomus duboscqi, Phlebotomus guggisbergi, and Phlebotomus pedifer (89). In some instances, there have been cases where individuals have been positive for both $L$. major and L. tropica (80). Transmission of L. aethiopica, L. major or L. tropica in Kenya is primarily thought to be zoonotic, with rodents, rock hyrax and dog being implicated in the transmission of parasites to humans $(82,90,91)$.

\section{UGANDA}

In Uganda, the visceral form of disease is endemic and was first reported in 1951 in the north east region of Karamoja (92). Familiarity of VL within the community is evident as it is known vernacularly as "Termes" to the Pokot people of Uganda (93). Several foci of VL are located across the Amarut, Moroto, Kotido, and Nakapiripirit districts of the Karamoja region which lies on the Kenyan border, where residents freely move between Uganda and the West Pokot and Baringo counties of Kenya (93, 94). It is thought that the vector involved in VL transmission to humans in this region is P. martini, similarly to Kenya, and the infective parasite species is L. donovani. There is currently a lack of data describing any possible reservoir hosts for $L$. donovani, as well as prevalence, incidence rates or risk factors in these endemic areas (93).

\section{SOMALIA}

The WHO reports that VL, but not CL, is endemic in Somalia, where incidence is 4.98 per 10,000 of the population in endemic areas (95). The causative species of VL in Somalia is identified as the L. donovani complex (96). Despite no definitive data confirming the competent vector, it is suspected that $P$. martini is a likely candidate in endemic areas due to few studies identifying its presence (97). As with most East African countries, VL is likely to be anthroponotic in Somalia, with no definite animal reservoir reported. Somalia has suffered from conflict for many years, which has restricted access to health care and impeded efforts for control and surveillance of infectious diseases, with the only current conceivable method of control being active case treatment (98). Healthcare provided by non-governmental organizations such as Médecins Sans Frontières (MSF), was withdrawn in 2013 due to ongoing violence and attacks on MSF workers rendering up to 1.5 million locals without health care and vulnerable to infectious diseases (99). The availability of epidemiological data for leishmaniasis in Somalia is rare (98). A few reports have documented VL endemic areas in Baidoa, lower Juba and middle Shebelle river, one citing the prevalence of VL seropositivity as high as $23 \%$ in one village $(98,100,101)$.

\section{ERITREA}

In Eritrea, there is a significant lack of data on the epidemiology of leishmaniasis. Few cases have been reported, mainly originating from the administrative regions on the Ethiopian and Sudanese side of the border, with a more recent case being described in the capital, Asmara $(38,102)$. Upon detection of leishmaniasis in Eritrea, the disease form is not distinguished and most commonly recorded as VL (103). Therefore, the overall extent of both disease forms is not clear (103). Currently, there are no control programmes, data defining vector species or reservoir hosts for Leishmania parasites in Eritrea (103).

\section{RISK FACTORS OF DISEASE}

Children and young adults are demographically most at risk of developing symptomatic leishmaniasis in endemic areas, potentially due to lack of protective immunity or due to them collecting water or playing in gorges close to sandfly habitat $(48,54,60)$. In areas with active outbreaks, all ages are at risk, with risk increasing with exposure to the vector (104).

Males may be more exposed than females, since they are more involved in outdoor agriculture or activity (38). Agriculture workers commonly work at night which coincides with the peak vector activity (53). Seasonal agricultural work sees a large influx of people moving from unaffected areas to endemic areas, such as the Ethiopian Humera plains near the Sudanese border, putting individuals at risk of VL (105). Similarly, infected individuals migrating from VL hotspots back to their homes serve as reservoirs for establishing new disease foci in previously unaffected areas (106).

Incidence in the north of Ethiopia is associated with cracking black cotton soil and Acacia-Balanite trees and termite hills and reddish clay soil in the south-the variation being due to the breeding site preferences of varying sandfly species (64).

Civil unrest, such as that seen in Sudan, can result in forced migration from endemic areas to non-endemic, further spreading the disease $(107,108)$. From 1983 until 2005, civil war between Sudan and South Sudan resulted in the uprooting and displacement of over 4 million people, which coincided with VL outbreaks and consequently 100,000 deaths over the 22 year period $(65,109,110)$. In subsequent years tension and unrest persisted, forcing millions of people to flee, with many immunologically naïve individuals migrating to endemic regions of neighboring countries such as the Omo plains or the Rift Valley (65). From the resumption of unrest in 2013, MSF reported that VL cases doubled in three endemic areas by 2014 (65).

Living near to, resting by or sleeping under Acacia-Balanite trees will increase the likelihood of exposure to the vector and thereby increase risk of disease in Ethiopia, Kenya, Somalia, and the Sudanese-Ethiopian borders (105). Additionally, proximity to dogs, cattle or termite hills increase the risk of exposure in endemic areas such as Libo Kemkem in Ethiopia (105).

Some species of sandfly are expected to be exophagic, and so sleeping outside increases the chance of sandfly bite $(42,111)$. Those subjected to living in poverty often own poor-quality housing (20). Houses with thatch walls or with no protective 
measures in place, such as bed nets or curtains, are more likely to be exposed to the vector $(105,108)$. With poverty often comes malnutrition, including lack of protein, iron, vitamin A and zinc levels which has been linked to VL development $(54,112)$. HIV-VL co-endemicity in north-west Ethiopia has resulted in coinfection rates of $20-40 \%$, where the associated immunosuppression aids VL development and HIV progression $(113,114)$. Other proposed risk factors include implementation of irrigation systems, the development of the sugar industry and forest clearance (45).

\section{CLIMATE CHANGE AND LEISHMANIASIS}

Increased global temperatures have resulted in increased flooding, droughts, land fires, and other destructive natural disasters. Since the 1880 s, the temperature has been steadily rising in increments of $0.07^{\circ} \mathrm{C}$, up until the past four decades, where this increased to $0.18^{\circ} \mathrm{C}(115)$. It is expected that climate warming will continue throughout the 21st century, with higher latitudes being more heavily impacted (116). Global warming has had a substantial impact on our environment and ecosystems and has altered the way humans live and move around. These two factors combined mean that human and infectious disease encounters will become more frequent and new environments will become more favorable to disease carrying vectors. Increased forest area clearance for land repurposing, urbanization, the building of roads, and water management structures are mirrored by an increase in emerging parasitic diseases (117).

The arthropod vectors responsible for transmitting the parasite, sandflies, are greatly impacted by changes to their ecology, resulting in changes in vector numbers, species present within an area, the mix of species within an area, and vector behaviors including, feeding, resting, or activity periods (117). In the $\mathrm{OW}$, there are 31 proven sandfly species with the ability to transmit Leishmania parasites (6). Knowledge of vector behavior is a crucial part of understanding disease transmission and allows for the development of vector control strategies (118). Sandflies are commonly found in warm countries with tropical or subtropical climates, notably Australia, the Americas, Asia, Africa, and the south of Europe, between $50^{\circ} \mathrm{N}$ and $40^{\circ} \mathrm{S}$ (119). Sandflies are considered thermophilic and so necessitate an environment where the average temperature is consistently high, as temperatures below $15^{\circ} \mathrm{C}$ will reduce survival rates in several species $(120,121)$.

Parasite development within the sandfly is optimum at temperatures around $25^{\circ} \mathrm{C}$, where higher temperatures decrease incubation time and permit faster transmission through increased reproduction in the midgut and movement through the sandfly (122). Heavy precipitation brought about by increased global temperatures will decrease flight ability, availability of landing surfaces, and can be fatal to larvae, however, some moisture within the soil of the sandfly environment is still required for survival. Despite this, as global warming intensifies, soil is likely to lack the required moisture due to fast evaporation rates as a result of long periods of sustained high temperatures and drought.

\section{LEISHMANIASIS, AN EMERGING PUBLIC HEALTH PROBLEM}

In the WHO European region, CL is endemic in Israel, Turkey, Uzbekistan, and Turkmenistan, whereas VL is much more widespread in the south-west of Europe, the Balkans, Turkey, Caucasus, and central Asia; with over $70 \%$ of VL cases in Italy, Spain, Albania, and Georgia (123). The parasites found in this region are $L$. infantum, $L$. tropica, and $L$. major, where CL is caused by all three species and VL by solely by $L$. infantum (123). The northern limit of sandfly distribution in Europe previously covered the south Mediterranean region and south eastern Europe (124). In recent years, there have been increases in the number of sporadic cases of leishmaniasis (cases identified by PCR as L. infantum or L. donovani/L. infantum) being reported from countries in central Europe including Germany, Austria, and in southern England (124-126). In southern European countries, there are several established sandfly species that are known to have the ability to host human-infective Leishmania parasites, including P. sergenti, P. papatasi, P. alexandri, P. tobbi, P. perniciosus, $P$. ariasi, P. perfiliewi, and P. neglectus (120). A rise in temperature by $1^{\circ} \mathrm{C}$ is suitable for survival of Phlebotomine sandflies in parts of Austria, such as the Slovenian border region, in which foci of leishmaniasis are likely to develop supported by canine reservoirs (124). Additionally, L. infantum DNA was detected from a caught sandfly (P. mascittii) in Austria (127). By 2040 more areas in the west and northwest of Germany are expected to become moderately or highly suitable for sandfly species survival (128). Sandflies were considered absent in Germany prior to 1999 but have now been found in BadenWürttemberg and were identified at 37 different sites in the Rhine Valley, Southwestern Germany $(129,130)$. Although the predominant species identified in this area is P.mascittii, in 2001 $P$. perniciosus sandflies were reported for the first time which have shown the ability to host $L$. infantum parasites (130). A recent ecological niche modeling study reported that the future climatic conditions could provide a suitable environment for sandfly species as far north as the UK and Scandinavia ( $P$. papatasi, P. tobbi, P. perniciosus, P.ariasi, P. perfiliewi, P. mascittii, and $P$. neglectus) (120). This is supported by another bioclimatic envelope modelling study which found that the central European climate will become more suitable for sandfly species currently found in the south-west of Europe, however dispersal of sandflies may also be inhibited by geographical barriers such as the Alps and sandfly flight ability (131). Around 100,000 dogs in Germany are estimated to be carrying Leishmania parasites (L. infantum) which could, given that there are competent vectors, act as reservoirs across the country (130). In addition to this, studies have revealed high numbers of asymptomatic L.infantum carriers in endemic regions, which suggests that humans could also act as reservoirs in new European foci (132).

The World Health Assembly resolution WHA 60.13 and WHO expert committee brought attention to the necessity leishmaniasis for epidemiology research, particularly in the European region, so that efficient policies, guidelines, and control strategies could be implemented to prevent further disease dissemination $(123,133)$. The WHO aim to prevent 
further spread of leishmaniasis by introducing surveillance, encouraging research on diagnostics and therapeutics, improving communication between collaborators and having epidemic management plans in place (123). Given the changes that are expected with climate change, it is fathomable that leishmaniasis could become a public health concern not only in the south of Europe, but central and north also. Suitable conditions for sandfly survival incorporated with factors such as increase in global travel and importation of reservoirs, such as dogs, from endemic countries where the disease is not efficiently managed could contribute to leishmaniasis outbreaks in these previously non-endemic countries. Similarly, in the Americas, with leishmaniasis already detected in Texas and Ohio, it has been predicted that the number of people exposed to leishmaniasis in North America will double by 2080 as leishmaniasis moves further north into the Americas, affecting east central North America and potentially southern Canada (134, 135). Ecological niche modeling of the impact climate change may have on both suspected vectors, Lutzomyia diabolica and Lutzomyia anthophora, and the woodrat reservoirs indicated their expansion of their habitats in North America, providing a wider environment suitable for Leishmania mexicana parasites (134). Although generally considered an imported disease in the US, either from travelers, the military or migrants, a study conducted in Texas demonstrated that $59 \%$ of identified leishmaniasis cases were autochthonous ( $32 \%$ of these cases were identified as L. mexicana, the other cases did not provide species information) (136). The underlying circulation of Leishmania parasites in animal reservoirs in this area may provide a starting point for expansion across North America as climate change ensues and vector and reservoir habitats expand. Despite this, in the US there is a possibility that the sandfly expansion can also be hindered, due to factors such as unsuitable landscape, species competition, and also geographical barriers (134).

\section{CONCLUSION}

Leishmaniasis remains a severe public health threat, particularly for those afflicted by poverty, war, living in conditions of poor nutrition and with impaired health systems. The East African region remains one of the most impacted regions globally and a lack of reporting with regards to the prevalence, distribution,

\section{REFERENCES}

1. WHO | World Health Organization. Neglected Trop Diseases Q \& A Detail. (2012). Available online at: https://www.who.int/news-room/q-adetail/neglected-tropical-diseases (accessed April 2, 2020).

2. WHO. Leishmaniasis Fact Sheet. World Health Organ (2020). Available online at: https:/www.who.int/news-room/fact-sheets/detail/leishmaniasis (accessed April 4, 2020).

3. Arenas R, Torres-Guerrero E, Quintanilla-Cedillo M.R, RuizEsmenjaud J. Leishmaniasis: a review. F1000Research. (2017) 6:750. doi: 10.12688/f1000research.11120.1

4. Walker DM, Oghumu S, Gupta G, McGwire BS, Drew ME, Satoskar AR. Mechanisms of cellular invasion by intracellular parasites. Cell Mol Life Sci. (2014) 71:1245-63. doi: 10.1007/s00018-013-1491-1 social/risk factors, and transmission of leishmaniasis continues to be a constraint to disease management in most afflicted countries. As our world continues to transform, both politically and climatically, it is essential that we understand the current epidemiology of leishmaniasis in endemic regions, that we improve surveillance and disease management and implement vector control where appropriate, especially in the low- and middle-income countries that are expected to be most impacted by changes in climate. Sporadic cases and Leishmania parasites have already been identified in canines in non-endemic central European countries, as well as southern states of the US. Regions of the world previously considered unaffected by leishmaniasis are predicted to become suitable to vector and reservoir of Leishmania species. Without a proper understanding of the disease in the endemic setting, we lack the ability to plan and efficiently implement disease control. For the leishmaniases, as for other neglected zoonoses, intervention costs can seem high when compared to the public health benefits alone. However, these costs are easily outweighed when a full cross-sector analysis is carried out and the monetary and non-monetary benefits to all stakeholders are taken into account. Only through effective management now, can we be sufficiently resilient to prevent the inevitable spread of infection with increased suitable vector habitat and prevention of expansion of the geographical range for leishmaniasis.

\section{AUTHOR CONTRIBUTIONS}

CJ and SW were both involved in conception, design, and writing of this perspective. Both authors read and approved the final version of the manuscript.

\section{FUNDING}

This research was also undertaken in part under Tackling Infections to Benefit Africa (TIBA) project commissioned by the National Institute for Health Research (NIHR) Global Health Research program (16/136/33) using UK aid from the UK Government (SW). The views expressed in this publication are those of the author(s) and not necessarily those of the Department of Health and Social Care.
5. Kevric I, Cappel MA, Keeling JH. New world and old world leishmania infections. Dermatol Clin. (2015) 33:579-93. doi: 10.1016/j.det.2015.03.018

6. Akhoundi M, Kuhls K, Cannet A, Votypka J, Marty P, Delaunay P, et al. A historical overview of the classification, evolution, and dispersion of Leishmania parasites and sandflies. PLoS Negl Trop Dis. (2016) 10:e0004349. doi: 10.1371/journal.pntd.0004349

7. Lainson R, Ryan L, Shaw JJ. Infective stages of Leishmania in the sandfly vector and some observations on the mechanism of transmission. Mem Inst Oswaldo Cruz. (1987) 82:421-4. doi: 10.1590/S0074-02761987000300015

8. Bogitsh BJ, Carter CE, Oeltmann TN. Chapter 18: Arthropods as vectors. In: Bogitsh BJ, Carter CE, Oeltmann TN, editors. Human Parasitology, 5th edn. London: Academic Press (2019). p. 331-60.

9. Aklilu E, Abbasi I, Gebresilassie A, Yared S, Kindu M, Kirstein OD, et al. Some aspects of entomological determinants of Phlebotomus orientalis in 
highland and lowland visceral leishmaniasis foci in northwestern Ethiopia. PLoS One. (2018) 13:e0192844. doi: 10.1371/journal.pone.0192844

10. Colmenares M, Kar S, Goldsmith-Pestana K, McMahonPratt D. Mechanisms of pathogenesis: differences amongst Leishmania species. Trans $R$ Soc Trop Med Hyg. (2002) 96(Suppl 1):S3-7. doi: 10.1016/S0035-9203(02)90044-1

11. Singh OP, Hasker E, Sacks D, Boelaert M, Sundar S. Asymptomatic leishmania infection: a new challenge for leishmania control. Clin Infect Dis Off Publ Infect Dis Soc Am. (2014) 58:1424-9. doi: 10.1093/cid/ciu102

12. Burza S, Croft SL, Boelaert M. Leishmaniasis. Lancet Lond Engl. (2018) 392:951-70. doi: 10.1016/S0140-6736(18)31204-2

13. Bilgic-Temel A, Murrell DF, Uzun S. Cutaneous leishmaniasis: a neglected disfiguring disease for women. Int J Womens Dermatol. (2019) 5:15865. doi: 10.1016/j.ijwd.2019.01.002

14. Aronson NE, Magill AJ. 104 - Leishmaniasis. In: Ryan ET, Hill DR, Solomon T, Aronson NE, Endy TP, editors. Hunter's Tropical Medicine Emerging Infectious Diseases, 10th edn. London: Content Repository Only (2020). p. 776-98.

15. Mans DR, Kent AD, VPF Hu R, Schallig HD. Epidemiological, biological and clinical aspects of leishmaniasis with special emphasis on busi yasi in suriname. J Clin Exp Dermatol Res. (2017) 08:2. doi: 10.4172/2155-9554.1000388

16. Juckett G. Chapter 33: Leishmaniasis. In: Walker PF, Barnett ED, editors. Immigrant Medicine. Edinburgh: W.B. Saunders (2007). p. 447-54.

17. Prieto-Granada CN, Lobo AZC, Mihm MC. Chapter 19: Skin infections. In: Kradin RL, editor. Diagnostic Pathology of Infectious Disease. New York, NY: W.B. Saunders (2010). p. 519-616.

18. Ryan ET, Hill DR, Solomon T, Endy TP, Aronson N. Hunter's Tropical Medicine and Emerging Infectious Diseases E-Book. Philadelphia, PA: Elsevier Health Sciences (2019).

19. Bennis I, Thys S, Filali H, De Brouwere V, Sahibi H, Boelaert M. Psychosocial impact of scars due to cutaneous leishmaniasis on high school students in Errachidia province, Morocco. Infect Dis Poverty. (2017) 6:46. doi: 10.1186/s40249-017-0267-5

20. Okwor I, Uzonna J. Social and economic burden of human leishmaniasis. Am J Trop Med Hyg. (2016) 94:489-93. doi: 10.4269/ajtmh.15-0408

21. Tamiru HF, Mashalla YJ, Mohammed R, Tshweneagae GT. Cutaneous leishmaniasis a neglected tropical disease: community knowledge, attitude and practices in an endemic area, Northwest Ethiopia. BMC Infect Dis. (2019) 19:855. doi: 10.1186/s12879-019-4506-1

22. WHO. Global Health Observatory Data Leishmaniasis. WHO. Available online at: http://www.who.int/gho/neglected_diseases/leishmaniasis/en/ (accessed April 2, 2020).

23. Strazzulla A, Cocuzza S, Pinzone MR, Postorino MC, Cosentino S, Serra A, et al. Mucosal leishmaniasis: an underestimated presentation of a neglected disease. BioMed Res Int. (2013) 2013:805108. doi: 10.1155/2013/805108

24. Scott P, Novais FO. Cutaneous leishmaniasis: immune responses in protection and pathogenesis. Nat Rev Immunol. (2016) 16:581-92. doi: 10.1038/nri.2016.72

25. Piscopo TV, Mallia Azzopardi C. Leishmaniasis. Postgrad Med J. (2007) 83:649-57. doi: 10.1136/pgmj.2006.047340corr1

26. Berkowitz FE. 267 - Leishmania Species (Leishmaniasis). In: Long SS, editor. Principles Practice of Pediatric Infectious Diseases, 4th edn. London: Content Repository Only (2012). p. 1285-91.e2.

27. van Griensven J, Gadisa E, Aseffa A, Hailu A, Beshah A.M, Diro E. Treatment of cutaneous leishmaniasis caused by leishmania aethiopica: a systematic review. PLoS Negl Trop Dis. (2016) 10:e0004495. doi: 10.1371/journal.pntd.0004495

28. Kumar R, Nylén S. Immunobiology of visceral leishmaniasis. Front Immunol. (2012) 3:251. doi: 10.3389/fimmu.2012.00251

29. Martins-Melo FR, Lima M da S, Ramos AN, Alencar CH, Heukelbach J. Mortality and case fatality due to visceral leishmaniasis in Brazil: a nationwide analysis of epidemiology, trends and spatial patterns. PLoS One. (2014) 9:e0093770. doi: 10.1371/journal.pone.0 093770

30. Lewis MD, Paun A, Romano A, Langston H, Langner CA, Moore IN, et al. Fatal progression of experimental visceral leishmaniasis is associated with intestinal parasitism and secondary infection by commensal bacteria, and is delayed by antibiotic prophylaxis. PLOS Pathog. (2020) 16:e1008456. doi: 10.1371/journal.ppat.1008456

31. Goto Y, Cheng J, Omachi S, Morimoto A. Prevalence, severity, and pathogeneses of anemia in visceral leishmaniasis. Parasitol Res. (2017) 116:457-64. doi: 10.1007/s00436-016-5313-x

32. Mundkur S, Shashidhara S, Hebbar S, Kanaparthi S. Case 3: Hepatosplenomegaly with Hyperpigmentation in a 6-year-old Girl. Pediatr Rev. (2019) 40:145-7. doi: 10.1542/pir.2017-0040

33. Bleeker-Rovers CP, De Vries HJC. 13 - Dermatologic manifestations of systemic infections. In: Cohen J, Powderly WG, Opal SM, editors. Infectious Diseases, 4th edn. Saint Louis: Elsevier (2017). p. 113-21.e1.

34. Sundar S. Visceral leishmaniasis. Trop Parasitol. (2015) 5:835. doi: 10.4103/2229-5070.162487

35. Alvar J, Velez ID, Bern C, Herrero M, Desjeux P, Cano J, Jannin J, et al. Leishmaniasis worldwide and global estimates of its incidence. PLoS One. (2012) 7:e35671. doi: 10.1371/journal.pone.0035671

36. Barley K, Mubayi A, Safan M, Castillo-Chavez C. A comparative assessment of visceral leishmaniasis burden in two eco-epidemiologically different countries, India and Sudan. bioRxiv 592220. (2019). doi: 10.1101/592220

37. Reithinger R, Brooker S, Kolaczinski JH. Visceral leishmaniasis in eastern Africa - current status. Trans R Soc Trop Med Hyg. (2007) 101:116970. doi: 10.1016/j.trstmh.2007.06.001

38. Malaria Consortium C. Leishmaniasis Control in Eastern Africa: Past and Present Efforts and Fututre Needs. Situation Gap Analysis (2010). Available online at: https://www.malariaconsortium.org/userfiles/file/ NTD\%20Resources/VL\%20EA\%20Situation\%20Analysis\%20Fina_Janl.pdf (accessed May 3, 2020).

39. Kassahun A, Sadlova J, Benda P, Kostalova T, Warburg A, Hailu A, et al. Natural infection of bats with Leishmania in Ethiopia. Acta Trop. (2015) 150:166-70. doi: 10.1016/j.actatropica.2015.07.024

40. Lemma A, Foster WA, Gemetchu T, Preston PM, Bryceson A, Minter DM. Studies on leishmaniasis in Ethiopia. I. Preliminary investigations into the epidemiology of cutaneous leishmaniasis in the highlands. Ann Trop Med Parasitol. (1969) 63:455-72. doi: 10.1080/00034983.1969.11686649

41. Cole ACE, Cosgrove PC, Robinson G. A preliminary report of an outbreak of kala-azar in a battalion of king's African rifles. Trans $R$ Soc Trop Med Hyg. (1942) 36:25-34. doi: 10.1016/S0035-9203(42)90053-1

42. Aschale Y, Ayehu A, Worku L, Tesfa H, Birhanie M, Lemma W. Malaria-visceral leishmaniasis co-infection and associated factors among migrant laborers in West Armachiho district, North West Ethiopia: Community based cross-sectional study. BMC Infect Dis. (2019) 19:239. doi: 10.1186/s12879-019-3865-y

43. Hailu A, Gramiccia M, Kager PA. Visceral leishmaniasis in Aba-Roba, south-western Ethiopia: prevalence and incidence of active and subclinical infections. Ann Trop Med Parasitol. (2009) 103:659-70. doi: 10.1179/000349809X12554106963555

44. The World Health Organisation. WHO - Leishmaniasis- Ethiopia-Country File 2015. (2017). Available online at: https://www.who.int/leishmaniasis/ burden/Ethiopia_2015-hl.pdf?ua=1 (accessed May 3, 2020).

45. Gebremichael D. Zoonotic impact and epidemiological changes of leishmaniasis in Ethiopia. Open Vet J. (2018) 8:43240. doi: 10.4314/ovj.v8i4.13

46. Seid A, Gadisa E, Tsegaw T, Abera A, Teshome A, Mulugeta A, et al. Risk map for cutaneous leishmaniasis in Ethiopia based on environmental factors as revealed by geographical information systems and statistics. Geospatial Health. (2014) 8:377-87. doi: 10.4081/gh.2014.27

47. Hailu A, Di Muccio T, Abebe T, Hunegnaw M, Kager PA, Gramiccia M. Isolation of Leishmania tropica from an Ethiopian cutaneous leishmaniasis patient. Trans R Soc Trop Med Hyg. (2006) 100:538. doi: 10.1016/j.trstmh.2005.04.017

48. van Henten S, Adriaensen W, Fikre H, Akuffo H, Diro E, Hailu A, et al. Cutaneous leishmaniasis due to Leishmania Aethiopica. EClinicalMedicine. (2018) 6:69-81. doi: 10.1016/j.eclinm.2018.12.009

49. Assefa A. Leishmaniasis in Ethiopia: a systematic review and metaanalysis of prevalence in animals and humans. Heliyon. (2018) 4:e00723. doi: 10.1016/j.heliyon.2018.e00723

50. Bekele F, Belay T, Zeynudin A, Hailu A. Visceral leishmaniasis in selected communities of Hamar and Banna-Tsamai districts in Lower Omo Valley, 
South West Ethiopia: Sero-epidemological and Leishmanin Skin Test Surveys. PLoS One. (2018) 13:e197430. doi: 10.1371/journal.pone.0197430

51. Gebremichael Tedla D, Bariagabr FH, Abreha HH. Incidence and trends of leishmaniasis and its risk factors in Humera, Western Tigray. J Parasitol Res. (2018) 2018:8463097. doi: 10.1155/2018/8463097

52. Dawit G, Shishay K. Epidemiology, public health impact and control methods of the most neglected parasite diseases in Ethiopia: a review. World J Med Sci. (2014) 10:94-102. doi: 10.5829/idosi.wjms.2014.10.2.81231

53. Gadisa E, Tsegaw T, Abera A, Elnaiem D.-E, Den Boer M, Aseffa A, et al. Ecoepidemiology of visceral leishmaniasis in Ethiopia. Parasit Vectors. (2015) 8:381. doi: 10.1186/s13071-015-0987-y

54. Leta S, Dao T.H.T, Mesele F, Alemayehu G. Visceral leishmaniasis in Ethiopia: an evolving disease. PLoS Negl Trop Dis. (2014) 8:e0003131. doi: 10.1371/journal.pntd.0003131

55. Alvar J, Bashaye S, Argaw D, Cruz I, Aparicio P, Kassa A, et al. Kala-azar outbreak in Libo Kemkem, Ethiopia: epidemiologic and parasitologic assessment. Am J Trop Med Hyg. (2007) 77:275-82. doi: 10.4269/ajtmh.2007.77.275

56. Bsrat A, Berhe N, Balkew M, Yohannes M, Teklu T, Gadisa E, et al. Epidemiological study of cutaneous leishmaniasis in Saesie Tsaedaemba district, eastern Tigray, northern Ethiopia. Parasit Vectors. (2015) 8:149. doi: 10.1186/s13071-015-0758-9

57. Bugssa G. The current status of cutaneous leishmaniasis and the pattern of lesions in Ochollo Primary School Students, Ochollo, Southwestern Ethiopia. Sci J Clin Med. (2014) 3:111. doi: 10.11648/j.sjcm.20140306.13

58. G D. A review on biology, epidemiology and public health significance of leishmaniasis. J Bacteriol Parasitol. (2013) 04:2. doi: 10.4172/2155-9597.1000166

59. Pareyn M, Van Den Bosch E, Girma N, Van Houtte $N$, Van Dongen S, Van Der Auwera G, et al. Ecology and seasonality of sandflies and potential reservoirs of cutaneous leishmaniasis in Ochollo, a hotspot in southern Ethiopia. PLoS Negl Trop Dis. (2019) 13:e0007667. doi: 10.1371/journal.pntd.0007667

60. Ashford RW, Bray MA, Hutchinson MP, Bray RS. The epidemiology of cutaneous leishmaniasis in Ethiopia. Trans $R$ Soc Trop Med Hyg. (1973) 67:568-601. doi: 10.1016/0035-9203(73)90088-6

61. Lemma W, Erenso G, Gadisa E, Balkew M, Gebre-Michael T, Hailu A. A zoonotic focus of cutaneous leishmaniasis in Addis Ababa, Ethiopia. Parasit Vectors. (2009) 2:60. doi: 10.1186/1756-3305-2-60

62. Bashaye S, Nombela N, Argaw D, Mulugeta A, Herrero M, Nieto J, et al. Risk factors for visceral leishmaniasis in a new epidemic site in Amhara region, Ethiopia. Am J Trop Med Hyg. (2009) 81:3439. doi: 10.4269 /ajtmh.2009.81.34

63. Hassan MM, Osman OF, El-Raba’a FMA, Schallig HDFH, Elnaiem DEA. Role of the domestic dog as a reservoir host of Leishmania donovani in eastern Sudan. Parasit Vectors. (2009) 2:26. doi: 10.1186/1756-3305-2-26

64. Gebresilassie A, Yared S, Aklilu E. Sandfly fauna and ecological analysis of Phlebotomus orientalis and Phlebotomus martini in the lowland foci of visceral leishmaniasis in Somali Regional State, southeast Ethiopia. Asian Pac J Trop Med. (2020) 13:31-7. doi: 10.4103/1995-7645.273572

65. Al-Salem W, Herricks JR, Hotez PJ. A review of visceral leishmaniasis during the conflict in South Sudan and the consequences for East African countries. Parasit Vectors. (2016) 9:460. doi: 10.1186/s13071-016-1743-7

66. Abebe A, Evans DA, Gemetchu T. The isolation of Leishmania aethiopica from the ground squirrel Xerus rutilus. Trans R Soc Trop Med Hyg. (1990) 84:691. doi: 10.1016/0035-9203(90)90147-7

67. Zink AR, Spigelman M, Schraut B, Greenblatt CL, Nerlich AG, Donoghue HD. Leishmaniasis in ancient Egypt and upper Nubia. Emerg Infect Dis. (2006) 12:1616-7. doi: 10.3201/eid1210.060169

68. Osman OF, Kager PA, Oskam L. Leishmaniasis in the Sudan: a literature review with emphasis on clinical aspects. Trop Med Int Health. (2000) 5:553-62. doi: 10.1046/j.1365-3156.2000.00598.x

69. The World Health Organisation. WHO Leishmaniasis Country File - Sudan 2015. (2015) Available online at: https://www.who.int/leishmaniasis/burden/ Sudan_2015_updated.pdf?ua=1 (accessed October 13, 2020).

70. Charani E, Cunnington AJ, Yousif AHA, Ahmed MS, Ahmed AEM, Babiker $\mathrm{S}$, et al. In transition: current health challenges and priorities in Sudan. BMJ Glob Health. (2019) 4:e001723. doi: 10.1136/bmjgh-2019-001723
71. Meheus F, Abuzaid AA, Baltussen R, Younis BM, Balasegaram M, Khalil EAG, et al. The economic burden of visceral leishmaniasis in Sudan: an assessment of provider and household costs. Am J Trop Med Hyg. (2013) 89:1146-53. doi: 10.4269/ajtmh.12-0585

72. Federal Ministry of Health. Manual for the Diagnostics and Treatment of Leishmaniasis. Republic of Sudan (2014).

73. Thomson MC, Bendall A, Osman ME, Schorscher J, Connor SJ, Obsomer $\mathrm{V}$, et al. RISK MAPPING OF VISCERAL LEISHMANIASIS: THE ROLE OF LOCAL VARIATION IN RAINFALL AND ALTITUDE ON THE PRESENCE AND INCIDENCE OF KALA-AZAR IN EASTERN SUDAN. Am J Trop Med Hyg. (2003) 68:10-7. doi: 10.4269/ajtmh.2003.68.1.0680010

74. Collis S, El-Safi S, Atia AA, Tapan Bhattacharyya, Hammad A, den Boer $\mathrm{M}$, et al. Epidemiological and molecular investigation of resurgent cutaneous leishmaniasis in Sudan. Int J Infect Dis. (2019) 88:1420. doi: 10.1016/j.ijid.2019.08.018

75. Khalid NM, Aboud MA, Alrabba FM, Elnaiem DEA, Tripet F. Evidence for genetic differentiation at the microgeographic scale in Phlebotomus papatasi populations from Sudan. Parasit Vectors. (2012) 5:249. doi: 10.1186/1756-3305-5-249

76. Elaagip A, Ahmed A, Wilson MD, Boakye DA, Hamid MMA. Studies of host preferences of wild-caught Phlebotomus orientalis and $\mathrm{Ph}$. papatasi vectors of leishmaniasis in Sudan. PLoS One. (2020) 15:e0236253. doi: 10.1371/journal.pone. 0236253

77. Dereure J, El-Safi SH, Bucheton B, Boni M, Kheir MM, Davoust B, et al. Visceral leishmaniasis in eastern Sudan: parasite identification in humans and dogs; host-parasite relationships. Microbes Infect. (2003) 5:11038. doi: 10.1016/j.micinf.2003.07.003

78. Elnaiem DA, Hassan MM, Maingon R, Nureldin GH, Mekawi AM, Miles M, et al. The Egyptian mongoose, Herpestes ichneumon, is a possible reservoir host of visceral leishmaniasis in eastern Sudan. Parasitology. (2001) 122:5316. doi: 10.1017/S0031182001007594

79. Okindo EG, Kutima HL, Mutai J, Kasili S. Attitude and practices of household heads towards leishmaniases infections in Marigat sub-county, Baringo County, Kenya. East Afr Med J. (2017) 94:86-94.

80. Ngure PK, Kimutai A, Ng'ang'a ZW, Rukunga G, Tonui WK. A review of Leishmaniasis in Eastern Africa. J Nanjing Med Univ. (2009) 23:7986. doi: 10.1016/S1007-4376(09)60032-0

81. Kolaczinski J.H, Reithinger R, Worku D.T, Ocheng A, Kasimiro J, Kabatereine N, et al. Risk factors of visceral leishmaniasis in East Africa: a case-control study in Pokot territory of Kenya and Uganda. Int J Epidemiol. (2008) 37:344-52. doi: 10.1093/ije/dym275

82. Tonui WK. Situational analysis of leishmaniases research in Kenya. Afr J Health Sci. (2006) 13:7-21. doi: 10.4314/ajhs.v13i1.30812

83. Mutero CM, Mutinga MJ, Ngindu AM, Kenya PR, Amimo FA. Visceral leishmaniasis and malaria prevalence in West Pokot District, Kenya. East Afr Med J. (1992) 69:3-8. PMID:1628545.

84. Kanyina EW. Characterization of visceral leishmaniasis outbreak, Marsabit County, Kenya, 2014. BMC Public Health. (2020) 20:446. doi: 10.1186/s12889-020-08532-9

85. WHO. Leishmaniasis Country Profile - Kenya 2015. (2015). Available online at: https://www.who.int/leishmaniasis/burden/Kenya_2015-hl.pdf? ua $=1$ (accessed October 10, 2020).

86. Ngere I, Gufu Boru W, Isack A, Muiruri J, Obonyo M, Matendechero $\mathrm{S}$, et al. Burden and risk factors of cutaneous leishmaniasis in a peri-urban settlement in Kenya, 2016. PLoS One. (2020) 15:e0227697. doi: 10.1371/journal.pone.0227697

87. Odiwuor S, Muia A, Magiri C, Maes I, Kirigi G, Dujardin JC, et al. Identification of Leishmania tropica from micro-foci of cutaneous leishmaniasis in the Kenyan Rift Valley. Pathog Glob Health. (2012) 106:15965. doi: 10.1179/2047773212Y.0000000015

88. Sang DK, Okelo GBA, Chance ML. Cutaneous leishmaniasis due to Leishmania aethiopica, on Mount Elgon, Kenya. Ann Trop Med Parasitol. (1993) 87:349-57. doi: 10.1080/00034983.1993.11812778

89. Owino BO, Matoke-Muhia D, Alraey Y, Mwangi JM, Ingonga JM, Ngumbi PM, et al. Association of Phlebotomus guggisbergi with Leishmania major and Leishmania tropica in a complex transmission setting for cutaneous leishmaniasis in Gilgil, Nakuru county, Kenya. PLoS Negl Trop Dis. (2019) 13:e0007712. doi: 10.1371/journal.pntd.0007712 
90. Mutinga MJ. The animal reservoir of cutaneous leishmaniasis on Mount Elgon, Kenya. East Afr Med J. (1975) 52:142-51.

91. The World Health Organisation. Leishmaniasis Kenya WHO Resources. Available online at: https://www.who.int/leishmaniasis/resources/KENYA. pdf?ua $=1$ (accessed December 12, 2020).

92. Mckinnon JA. Kala-azar in the Upper Rift Valley of Kenya. Part I. Background and discovery of the disease. J Trop Med Hyg. (1962) 65:51-63.

93. Ministry of Health Uganda. Guidlines for the Diagnosis, Treatment and Prevention of Visceral Leishmaniasis in Uganda. Ministry of Health Uganda (2019). Available online at: https://www.who.int/leishmaniasis/burden/ $\mathrm{MOH}$ _Uganda_Guidelines_diagnosis_treatment_prevention_VL.pdf?ua $=1$ (accessed December 12, 2020).

94. Olobo-Okao J, Sagaki P. Leishmaniasis in Uganda: historical account and a review of the literature. Pan Afr Med J. (2014) 18:16. doi: 10.11604\%2Fpamj.2014.18.16.1661

95. The World Health Organisation. WHO Leishmaniasis Country Profile - Somalia 2015. (2015) Available online at: https://www.who.int/ leishmaniasis/burden/Somalia_2015-hl.pdf?ua=1 (accessed December 12, 2020).

96. Marlet MVL, Wuillaume F, Jacquet D, Quispe KW, Dujardin JC, Boelaert M. A neglected disease of humans: a new focus of visceral leishmaniasis in Bakool, Somalia. Trans R Soc Trop Med Hyg. (2003) 97:66771. doi: 10.1016/S0035-9203(03)80099-8

97. Elnaiem D-EA. Ecology and control of the sand fly vectors of Leishmania donovani in East Africa, with special emphasis on Phlebotomus orientalis. $J$ Vector Ecol. (2011) 36:S23-S31. doi: 10.1111/j.1948-7134.2011.00109.x

98. Sunyoto T, Potet J, Boelaert M. Visceral leishmaniasis in Somalia: a review of epidemiology and access to care. PLoS Negl Trop Dis. (2017) 11:e0005231. doi: 10.1371/journal.pntd.0005231

99. Burki TK. Somalia: a gathering storm? The Lancet. (2013) 382:123738. doi: 10.1016/S0140-6736(13)62083-8

100. Shiddo SA, Mohamed AA, Akuffo HO, Mohamud KA, Herzi AA, Mohamed $\mathrm{HH}$, et al. Visceral leishmaniasis in Somalia: prevalence of markers of infection and disease manifestations in a village in an endemic area. Trans R Soc Trop Med Hyg. (1995) 89:361-5. doi: 10.1016/0035-9203(95) 90008-X

101. Shiddo SA, Akuffo HO, Mohamed AA, Huldt G, Nilsson L-A, Ouchterlony Ö, et al. Visceral leishmaniasis in Somalia: prevalence of leishmanin-positive and seropositive inhabitants in an endemic area. Trans $\mathrm{R}$ Soc Trop Med Hyg. (1995) 89:21-4. doi: 10.1016/0035-9203(95)90640-1

102. Alamin AA. Visceral Leishmaniasis in a Non-endemic Region of Eritrea. Cureus. (2020) 12:e11318. doi: 10.7759/cureus.11318

103. The World Health Organisation. Leishmaniasis Eritrea WHO Resources. Available online at: https://www.who.int/leishmaniasis/resources/ERITREA. pdf (accessed December 12, 2020).

104. Ali A, Ashford R.W. Visceral leishmaniasis in Ethiopia. IV. Prevalence, incidence and relation of infection to disease in an endemic area. Ann Trop Med Parasitol. (1994) 88:289-93. doi: 10.1080/00034983.1994.118 12869

105. Argaw D, Mulugeta A, Herrero M, Nombela N, Teklu T, Tefera T, et al. Risk factors for visceral Leishmaniasis among residents and migrants in Kafta-Humera, Ethiopia. PLoS Negl Trop Dis. (2013) 7:e2543. doi: 10.1371/journal.pntd.0002543

106. Ayehu A, Aschale Y, Lemma W, Alebel A, Worku L, Jejaw AG, et al. Seroprevalence of asymptomatic leishmania donovani among laborers and associated risk factors in agricultural camps of west Armachiho District, Northwest Ethiopia: a cross-sectional study. J Parasitol Res. (2018) 2018:5751743. doi: 10.1155/2018/5751743

107. World Health Organization. Response. WHO. Available online at: https:// www.who.int/leishmaniasis/epidemic/response_more/en/ (accessed April 30, 2020).

108. Alvar J, Yactayo S, Bern C. Leishmaniasis and poverty. Trends Parasitol. (2006) 22:552-7. doi: 10.1016/j.pt.2006.09.004

109. Zijlstra EE, El-Hassan AM. 3. Visceral leishmaniasis. Trans R Soc Trop Med Hyg. (2001) 95:S27-S58. doi: 10.1016/S0035-9203(01)90218-4

110. Wakabi W. Peace has come to southern Sudan, but challenges remain. Lancet. (2006) 368:829-30. doi: 10.1016/S0140-6736(06)69307-0
111. Custodio E, Gadisa E, Sordo L, Cruz I, Moreno J, Nieto J, et al. Factors associated with leishmania asymptomatic infection: results from a crosssectional survey in highland Northern Ethiopia. PLoS Negl Trop Dis. (2012) 6:e1813. doi: 10.1371/journal.pntd.0001813

112. Mengesha B, Endris M, Takele Y, Mekonnen K, Tadesse T, Feleke A, et al. Prevalence of malnutrition and associated risk factors among adult visceral leishmaniasis patients in Northwest Ethiopia: a cross sectional study. BMC Res Notes. (2014) 7:75. doi: 10.1186/1756-0500-7-75

113. Diro E, Blesson S, Edwards T, Ritmeijer K, Fikre H, Admassu H, et al. A randomized trial of AmBisome monotherapy and AmBisome and miltefosine combination to treat visceral leishmaniasis in HIV co-infected patients in Ethiopia. PLoS Negl Trop Dis. (2019) 13:e000698. doi: 10.1371/journal.pntd.0006988

114. Diro E, Lynen L, Ritmeijer K, Boelaert M, Hailu A, van Griensven J. Visceral Leishmaniasis and HIV coinfection in East Africa. PLoS Negl Trop Dis. (2014) 8:e2869. doi: 10.1371/journal.pntd.0002869

115. National Centers for Environmental Information. NOAA National Centers for Environmental Information, State of the Climate: Global Climate Report for Annual 2019. (2020) Available online at: https://www.ncdc.noaa.gov/sotc/ global/201913 (accessed October 10, 2020).

116. Carvalho BM, Rangel EF, Vale MM. Evaluation of the impacts of climate change on disease vectors through ecological niche modelling. Bull Entomol Res. (2017) 107:419-30. doi: 10.1017/S0007485316001097

117. Patz JA, Graczyk TK, Geller N, Vittor AY. Effects of environmental change on emerging parasitic diseases. Int J Parasitol. (2000) 30:1395405. doi: 10.1016/S0020-7519(00)00141-7

118. Wilson AL, Courtenay O, Kelly-Hope LA, Scott TW, Takken W, Torr SJ, et al. The importance of vector control for the control and elimination of vector-borne diseases. PLoS Negl Trop Dis. (2020) 14:e0007831. doi: 10.1371/journal.pntd.0007831

119. Maroli M, Feliciangeli MD, Bichaud L, Charrel RN, Gradoni L. Phlebotomine sandflies and the spreading of leishmaniases and other diseases of public health concern. Med Vet Entomol. (2013) 27:123-47. doi: 10.1111/j.1365-2915.2012.01034.x

120. Koch LK, Kochmann J, Klimpel S, Cunze S. Modeling the climatic suitability of leishmaniasis vector species in Europe. Sci Rep. (2017) 7:13325. doi: 10.1038/s41598-017-13822-1

121. Kasap OE, Alten B. Comparative demography of the sand fly Phlebotomus papatasi (Diptera: Psychodidae) at constant temperatures. J Vector Ecol. (2006) 31:378-85. doi: 10.3376/1081-1710 (2006) 31[378:CDOTSF]2.0.CO;2

122. Rioux JA, Dereure J, Daoud W, el Kubati Y, Rageh HA, Moreno G, et al. Ecoepidemiology of visceral and cutaneous leishmaniasis in the Yemen Arab Republic. I. Presence, in sympatric condition, of Leishmania infantum and Leishmania donovani complexes. Bull Soc Pathol Exot Filiales. (1989) 82:65864.

123. The World Health Organisation. Leishmaniasis in the WHO European Region Fact Sheet. Available online at: https://www.euro.who.int/_data/assets/pdf_ file/0007/246166/Fact-sheet-Leishmaniasis-Eng.pdf (accessed December 12, 2020).

124. Aspöck H, Gerersdorfer T, Formayer H, Walochnik J. Sandflies and sandflyborne infections of humans in Central Europe in the light of climate change. Wien Klin Wochenschr. (2008) 120:24-9. doi: 10.1007/s00508-008-1072-8

125. Darne S, Sinclair SA. A sandfly in Surrey? A case of cutaneous leishmaniasis in the United Kingdom without history of recent travel to an endemic area. Clin Exp Dermatol. (2006) 31:155-6. doi: 10.1111/j.1365-2230.2005.01984.x

126. Bogdan C, Schonian G, Banuls A-L, Hide M, Pratlong F, Lorenz E, et al. Visceral Leishmaniasis in a German child who had never entered a known endemic area: Case Report and Review of the Literature. Clin Infect Dis. (2001) 32:302-6. doi: 10.1086/318476

127. Obwaller AG, Karakus M, Poeppl W, Töz S, Özbel Y, Aspöck H, Walochnik J. Could Phlebotomus mascittii play a role as a natural vector for Leishmania infantum? New data. Parasit Vectors. (2016) 9:458. doi: 10.1186/s13071-016-1750-8

128. Haeberlein S, Fischer D, Thomas SM, Schleicher U, Beierkuhnlein C, Bogdan C. First assessment for the presence of phlebotomine vectors in Bavaria, Southern Germany, by Combined Distribution Modeling and Field Surveys. PLoS One. (2013) 8:e81088. doi: 10.1371/journal.pone.0081088 
129. Naucke TJ, Pesson B. Presence of Phlebotomus (Transphlebotomus) mascittii Grassi, 1908 (Diptera: Psychodidae) in Germany. Parasitol Res. (2000) 86:335-6. doi: 10.1007/s004360050053

130. Oerther S, Jöst H, Heitmann A, Lühken R, Krüger A, Steinhausen I, et al. Phlebotomine sand flies in Southwest Germany: an update with records in new locations. Parasit Vectors. (2020) 13:173. doi: 10.1186/s13071-020-04058-6

131. Fischer D, Moeller P, Thomas SM, Naucke TJ, Beierkuhnlein C. Combining climatic projections and dispersal ability: a method for estimating the responses of sandfly vector species to climate change. PLoS Negl Trop Dis. (2011) 5:e1407. doi: 10.1371/journal.pntd.0001407

132. Michel G, Pomares C, Ferrua B, Marty P. Importance of worldwide asymptomatic carriers of Leishmania infantum (L. chagasi) in human. Acta Trop. (2011) 119:69-75. doi: 10.1016/j.actatropica.2011.05.012

133. WHO Expert Committee on the Control of the Leishmaniases \& World Health Organization (2010). Control of the Leishmaniases: Report of a Meeting of the WHO Expert Commitee on the Control of Leishmaniases. Geneva: World Health Organization (2010). Available online at: https://apps. who.int/iris/handle/10665/44412 (accessed December 12, 2020).

134. González C, Wang O, Strutz SE, González-Salazar C, Sánchez-Cordero V, Sarkar S. Climate change and risk of leishmaniasis in North America:
Predictions from ecological niche models of vector and reservoir species. PLoS Negl Trop Dis. (2010) 4:e585. doi: 10.1371/journal.pntd.0000585

135. Moo-Llanes D, Ibarra-Cerdeña CN, Rebollar-Téllez EA, Ibáñez-Bernal S, González C, Ramsey JM. Current and future niche of North and Central American Sand Flies (Diptera: Psychodidae) in climate change scenarios. PLoS Negl Trop Dis. (2013) 7:e2421. doi: 10.1371/journal.pntd.00 02421

136. McIlwee BE, Weis SE, Hosier GA. Incidence of Endemic Human Cutaneous Leishmaniasis in the United States. JAMA Dermatol. (2018) 154:10329. doi: 10.1001/jamadermatol.2018.2133

Conflict of Interest: The authors declare that the research was conducted in the absence of any commercial or financial relationships that could be construed as a potential conflict of interest.

Copyright (c) 2021 Jones and Welburn. This is an open-access article distributed under the terms of the Creative Commons Attribution License (CC BY). The use, distribution or reproduction in other forums is permitted, provided the original author(s) and the copyright owner(s) are credited and that the original publication in this journal is cited, in accordance with accepted academic practice. No use, distribution or reproduction is permitted which does not comply with these terms. 